\title{
A Importância da Política de Formação Continuada no Desempenho dos Servidores Público
}

\author{
Marilene Neri Brasil \\ Universidade Estadual do Ceará - UECE \\ Profa. Dra. Kátia Paulino dos Santos \\ Universidade Estadual do Ceará - UECE
}

\begin{abstract}
Resumo
O Brasil ao longo dos anos vem buscando organizar e reorganizar a administração pública, com desdobramentos da profissionalização do servidor público através da capacitação e formação continuada. Desde a vinda da família real portuguesa ao Brasil até os dias atuais se tem buscado através de legislações tímidas, prestar serviços de qualidade à população brasileira. Para tanto, foi criado as Escolas de Governo no Brasil, sob a ótica da formação e capacitação do servidor público, sendo que no Amapá, em 2009, foi criada a Escola de Administração Pública-EAP, com objetivo de planejar e executar a política de formação dos servidores estaduais. Neste sentido, o objetivo central deste estudo foi analisar as contribuições da EAP para a formação dos servidores do Estado do Amapá, por meio de pesquisa qualitativa, haja vista que considerou a relação dinâmica entre a realidade dos serviços prestados à população e as capacitações realizadas pela mesma, sendo que do ponto de vista do objetivo foi realizado uma pesquisa explicativa, pois fora analisado o levantamento de dados das avaliações de reação dos servidores, bem como as entrevistas com os diversos autores do processo, explicando-se os as relações pesquisadas por meio dos dados obtidos. É valido ressaltar que a pesquisa mostrou nesta política pública, a falta de acompanhamento sistematizado dos servidores referente às necessidades de capacitação e aproveitamento, explicitando a necessidade premente de melhoria na política pela qual a EAP é responsável.
\end{abstract}

Palavra-chave serviço público; formação continuada; escola de governo; escola de administração pública.

\begin{abstract}
Brazil over the years has been seeking to organize and reorganize the public administration, with consequences of the professionalization of the public servant through training and continuing education. From the arrival of the Portuguese royal family to Brazil to the present day, it has sought, through timid legislation, to provide quality services to the Brazilian population. To this end, the Government Schools were created in Brazil, from the perspective of the training and qualification of public servants, and in Amapá, in 2009, the Public Administration School-EAP was created, with the objective of planning and executing the policy of training of state employees. In this sense, the main objective of this study was
\end{abstract}


to analyze the contributions of EAP to the training of civil servants in the State of Amapá, through qualitative research, given that it considered the dynamic relationship between the reality of services provided to the population and the training provided by same, and from the point of view of the objective, an explanatory research was carried out, as the data collection of the reaction evaluations of the servers was analyzed, as well as the interviews with the various authors of the process, explaining the relationships researched through obtained data. It is worth noting that the research showed in this public policy, the lack of systematic monitoring of civil servants regarding training and utilization needs, explaining the pressing need for improvement in the policy for which EAP is responsible.

Key-word public service; public policy; continuing education; school of government.

\section{Introdução}

A administração pública tem buscado melhorias na sua execução, o que tem implicado em alterações, no que se refere a sua atuação frente aos serviços prestados a população, sendo que o principal ator para a efetivação dessa mudança é o próprio agente público, o servidor.

Assim, é necessário desenvolver estratégias que venham favorecer a melhoria dos serviços. Dentre elas destaca-se o desenvolvimento de valores, tanto para o gestor, quanto para o servidor que atua na linha de frente junto à população, pois a função pública precisa, efetivamente, se profissionalizar.

Neste contexto, visando o desenvolvimento da profissionalização do servidor público, qualificado, preparado a enfrentar esse novo cenário, são criadas no Brasil as primeiras "Escolas de Governo" na década de 80, referendada no Art. 39, § 2ㅇ da Constituição Federal de 1988, com missão, finalidades e desafios próprios de cada Estado, mas ainda com alguns conflitos de foco. Sendo que na década seguinte, começaram a tomar novos rumos, adotando o conceito de "formação continuada", aplicando-os na capacitação de diversos segmentos do serviço púbico Federal, Estadual e Municipal.

É fundamental repensar a própria organização do trabalho público para que essa acompanhe tais avanços e para que se torne um espaço digno para os novos cidadãos e novos servidores do público. Deve-se ainda pensar os espaços de trabalho sob uma ótica formadora, avançando além das tradicionais concepções e práticas de formação dos servidores públicos.

Frente a esta imprescindível mudança, o Estado deve adequar os serviços prestados de forma que venha dar respostas aos anseios da sociedade, pois os serviços precisam ser mais céleres, otimizando os recursos existentes, criando novas oportunidades e assumindo suas reais funções. Nesse sentido, a formação do servidor deve estar alinhada com uma política pública de valorização de formação descentralizada e adequada a regionalização dos serviços prestados a população como bem público, com diretrizes e objetivos claros ao que se pretende alcançar, consolidando a relação entre Estado e sociedade.

Neste viés, o Estado do Amapá em 2009 implanta a Escola de Administração PúblicaEAP, com o intuito de integrar os desafios estratégicos de governo, ao mesmo tempo em que deve analisar e dar respostas às novas tendências do setor público, como também possibilitando oportunidade de formação continuada aplicada às necessidades da sociedade. 
Neste contexto, este estudo buscou identificar a contribuição da formação continuada viabilizada pela Escola de Administração Pública para a melhoria do desempenho profissional dos servidores públicos estaduais, no período de 2013-2016.

Vislumbrar-se-á os desdobramentos desse estudo em capítulos que perpassam desde o olhar histórico da Gestão Pública, as escolas de governo no Brasil, o contexto do Estado do Amapá e a Escola de Administração Pública até as considerações finais sob a ótica dos dados obtidos por meio dos estudos de caso.

\section{Metodologia da pesquisa}

Para o alcance dos objetivos propostos, se utilizou de pesquisa qualitativoexplicativa, tendo como objeto de estudo a atuação da Escola de Administração Pública, no Estado do Amapá frente às capacitações dos servidores públicos estaduais no marco temporal de 2013 - 2016. Utilizou-se ainda como aprofundamento, estudos de caso aplicados em 03 órgãos de governo, dos quais a Secretaria de Estado da Administração (SEAD), Comando Geral da Polícia Militar do Amapá e Comando Geral do Corpo de Bombeiros do Amapá. Todos fazendo parte da administração pública direta do Estado do Amapá.

Para tanto, foram utilizados como instrumentos de pesquisa documentos estratégicos de avaliação como relatórios de gestão, avaliações de reação, entrevistas estruturadas com os gestores, chefes imediatos e servidores públicos estaduais capacitados pela Escola no decorrer do marco temporal em estudo, sendo desenvolvida a sistematização e análise dos dados.

A partir das concepções teóricas que nortearam a pesquisa, a mensuração dos dados e análises dos mesmos foi possível estabelecer um diagnóstico quanto a efetividade da Escola de Administração, capacitações realizadas e reflexo das mesmas na atuação dos servidores públicos do estado do Amapá.

\section{Gestão pública no Brasil: um olhar histórico}

A gestão púbica no Brasil, ao longo dos anos, tem passado por diversas buscas de transformações e atualizações de acordo com o momento político, econômico e social vivenciado. Neste sentido, necessário se faz apresentar algumas considerações acerca desse processo tão importante para a sociedade brasileira.

A reforma da gestão pública, de acordo com Pereira (1998), começou a tomar forma praticamente em todo o mundo nos anos 70, mas no Brasil iniciou em meio a crise econômica da década de 90, com a hiperinflação. Tornou-se tema de extrema relevância em termos mundiais, sendo também uma resposta ao processo de globalização, o qual reduziu a autonomia dos estados em planejar e implementar políticas, estando atreladas à crise do Estado.

Para tanto, Bittencourt e Zouain (2010) preconizam que se recomenda aparelhamento burocrático estável, livre das descontinuidades administrativas e competente, devidamente preparado para adoção de inovações organizacionais e de modernas técnicas de gestão, habilitado a formular, executar, monitorar e avaliar políticas públicas capazes de responder a desafios contemporâneos. Para adquirir essa consciência e estar pronto para essa tarefa, o servidor precisa internalizar valores, e a função pública precisa, efetivamente, se profissionalizar. Reformar a gestão pública brasileira, como 
qualquer política pública, depende de inúmeras variáveis, interesses e acordos. Requer constituição de alianças entre os sujeitos estratégicos que precisam ser convencidos da importância desse tema, bem como, uma mudança cultural por parte dos servidores públicos.

\section{Políticas públicas no Brasil: origem e evolução}

Buscando apresentar a ideia do que é política pública, a fim de contextualizar e ampliar o olhar sobre o objeto desta pesquisa, e assim subsidiar a compreensão do todo, se estudou e analisou diversos autores que discutem sobre essa temática.

Segundo Flexor e Leite (2006), políticas públicas são fruto de um processo político que busca nivelar as preferências dos atores com os interesses das organizações e instituições. Tem-se a exemplo, os políticos que estão motivados por (re)eleições e votarão em políticas que favoreçam os interesses de seus eleitores, a administração pública e o aparato burocrático, buscando influenciar o cerne das políticas para promover as necessidades de suas organizações. Pois bem, de uma forma simplista infere-se que políticas públicas são procedimentos e orientações que direcionam a política administrativa de um Estado, regulando as atividades de um governo no que se refere às ações de interesse público.

A gestão pública deve aplicar as políticas públicas não somente como instrumento orçamentário, como mera transferência de renda ou assistencialista, é necessário ir mais além, respondendo às demandas da sociedade por bens e serviços públicos de qualidade. Para Fernandes (2013), tem sido percebida a necessidade de que as definições de políticas públicas sejam alinhadas às características socioeconômicas que singularizam os grupos.

As políticas públicas desta forma, não possuem condições de isenção da interferência política, mas em contrapartida apresenta a inter-relação de ideias e interesses entre os grupos da sociedade e grupos políticos, agregando e buscando o atendimento de ambos, desde que haja recursos para isso. Entretanto, para Fernandes (2013), os desafios para a implementação de políticas públicas perpassam a superação da lógica que institui fronteiras entre setores e pela construção de estratégias que considerem a diversidade regional. 0 primeiro relaciona-se à complexidade da dinâmica social e à dificuldade de enfrentar os problemas partindo de ações fragmentadas e desarticuladas. 0 segundo trata de reconhecer que as particularidades culturais, econômicas e sociais têm impacto nas prioridades estabelecidas para um determinado território e, assim, na forma de implementação das políticas públicas.

E Rua (1997) conclui que política pública é assim, porque na realidade o que existe não é um processo acabado, mas sim um contínuo movimento de interação entre uma política em mudança, uma estrutura de relações de grande complexidade e um mundo exterior não apenas complexo, mas também dotado de uma dinâmica cada vez mais acelerada. Cabe aos diversos atores envolvidos na aplicabilidade da política pública, auxiliar em todos os processos inerentes a consecução da mesma e assim atingir aos objetivos.

\section{As Escolas de Governo no Brasil}

Com a evolução da administração pública e a grande necessidade de formação continuada dos servidores públicos, em busca da profissionalização, tendo em vista os novos cenários da sociedade, o Brasil foi buscar nas experiências internacionais, modelos 
de escola de governo, para assim sistematizar as formações iniciais e as formações continuadas.

Assim, Ferreira (2011), explica o esforço iniciado na década de 1940, com a proposta de instituir no país um centro de estudos em administração pública. Inicialmente com o apoio da ONU, instalou-se no Rio de Janeiro, em 1944, a Fundação Getúlio Vargas. Em 1952 foi criada, no Rio de Janeiro, a primeira Escola Brasileira de Administração Pública (EBAP), contando com o apoio e atuação de docentes americanos, voltados para a formação e treinamento de servidores, mas prioritariamente dedicadas ao segmento dos servidores seniores.

Conforme se infere sobre a trajetória descrita ao longo da história, a criação de uma organização seja na forma de escola ou de centro de treinamento, foi proposta em dois momentos como uma conexão que viabilizasse a constituição de um sistema de recrutamento e formação de quadros para atuação nos escalões superiores e de fortalecimento de uma identidade e cultura do serviço civil, ou seja, a profissionalização do servidor público.

\section{O papel institucional das escolas: avanços e entraves}

De forma geral, as escolas de governo não possuem uma convergência no que se refere à base de uma matriz estratégica e a realização de rotinas de planejamento. Nem tão pouco, apresentam em seus normativos princípios e valores que orientam a atuação da escola, assim como as suas finalidades de maneira ampla. Tal cenário de divergências representa a articulação do Estado frente aos objetivos que se deseja alcançar junto aos servidores e a Administração púbica.

As Escolas de Governo podem ser classificadas em dois grandes grupos, conforme destaca Zouain (2003). No primeiro, reúnem-se as instituições criadas com a missão de capacitar, nos mais diversos níveis, os profissionais vinculados a áreas e a carreiras específicas de atuação do Estado. No segundo, estão instituições que, não obstante atuarem com capacitação do setor público, não se vinculam, especificamente, a nenhuma carreira de Estado. Têm sua atuação voltada para o grande contingente de servidores distribuídos em todos os níveis e áreas da burocracia. Para tanto, as organizações e as pessoas precisam estar dispostas a aprender continuamente, a fim de diminuir a defasagem, própria da dinâmica organizacional, entre as competências que existem atualmente e aquelas que precisam ser desenvolvidas.

0 grande desafio das escolas de governo, segundo Carvalho et al (2009), é articular a gestão da educação para o trabalho com o referencial de competências. Isso significa pensar como usar a noção de competência para alimentar a definição das necessidades de capacitação. Nessa perspectiva, e no atual cenário, a realização de parcerias se configura como um dos mais importantes quesitos para a atuação eficaz e eficiente das escolas de governo. Assim, em 2003, de acordo com Amaral (2004) a ENAP incentivou a formação da Rede Nacional de Escolas de Governo, uma rede de estímulo voluntário a conexões, com o intuito de aproveitar a riqueza da diversidade e articular a complementaridade, objetivando ampliar a eficácia das instituições que trabalham com formação e aperfeiçoamento profissional dos servidores públicos das três esferas de governo, apesar das limitações apresentadas. 


\section{O Estado do Amapá e a Escola de Administração Pública}

O Estado do Amapá é uma das 27 unidades federativas do Brasil. Está situado a nordeste da Região Norte, no Platô das Guianas. 0 Amapá foi desmembrado do estado do Pará em 1943, quando foi criado o Território Federal do Amapá (TFA). Permaneceu nesta condição até 1988, quando a atual Constituição Federal o elevou a estado da Federação.

De acordo com estimativas do Instituto Brasileiro de Geografia e Estatística (IBGE), sua população era de 829494 habitantes em 2018 e, de acordo com os dados obtidos no portal da transparência do governo do estado do Amapá, atualmente há aproximadamente 33.000 servidores públicos, distribuídos em 62 órgãos da administração direta e indireta, existentes nos 16 municípios do Estado, sendo que a maioria dos servidores atua na região metropolitana.

0 Estado se mobilizou no sentido de ampliar esse processo de formação e profissionalização do servidor, e em 05 de janeiro de 2009, publicando a Lei no 1289 que altera dispositivos da Lei no 0811 de 2004, legitimando a criação da Escola de Administração Pública do Amapá - EAP, a qual tem por finalidade "planejar, executar, acompanhar, monitorar e avaliar a política de formação, qualificação, desenvolvimento de pessoal, e valorização do servidor, no âmbito do Poder Executivo Estadual”.

Diante desse cenário, a escola de governo do Amapá tem como perfil principal as capacitações através de cursos livres de formação continuada, palestras, cursos de pósgraduação lato e stricto sensu, legitimados através de metas anuais estabelecidas no Plano Plurianual, o PPA do Estado, através dos principais Programas: Consultoria, Pós-Graduação, formação e desenvolvimento técnico, gerencial e pessoal, divulgação do servidor e estágio, com metas estabelecidas no PPA que norteiam os objetivos e dados quantitativos a serem alcançados a cada ano, mensurados para posterior análise e elaboração de novos rumos e novas ações políticas de formação ou apenas de aprimoramento.

\section{A Escola de Admnistração Pública sob o olhar dos gestores e servidores públicos}

Nos anos de 2013-2014 o ambiente da Escola de Administração Pública era muito produtivo, porém de acordo com a análise do ex-diretor, o cenário poderia ser melhor quanto as formações oferecidas tornando-as mais atrativas, uma vez ser recorrente o esvaziamento ou abandono de alguns cursos, justificando-se pelo fato que a certificação da escola ser considerada "sem valor" pelos cursistas. A EAP precisa ser reconhecida pelos sistemas de formações, seja pelo MEC, CEE ou outro sistema. É necessário que o servidor internalize que a certificação da EAP é importante para sua carreira.

Outro ponto crucial enfatizado pelo ex-diretor se trata da modernização da EAP, através de uma política institucional mais arrojada com a oferta de cursos vinculados a carreira do servidor, sendo critério para progressão e promoção. A estrutura física da escola também é incompatível com a demanda de formação e profissionalização do servidor público do Estado do Amapá, assim como a estrutura de cargos é pequena demais para os desafios que a EAP tem em sua finalidade.

O cenário do biênio 2015-2016 foi bem diferente do primeiro analisado. 0 Brasil mergulhou numa crise econômica, e no Amapá não foi diferente, em virtude da diminuição no arrecadamento tributário, dos repasses advindos do governo federal e outras dificuldades vivenciadas naquele momento e que perduram nos dias atuais, pois se iniciou 
um novo governo no estado, havendo cortes e contingenciamento orçamentário para todos os órgãos do governo, inclusive da EAP.

A Diretora Presidente da EAP nesse período enfatizou que o orçamentário e financeiro sempre foram um problema para a instituição, e que o planejamento das formações disponibilizadas pela EAP era realizado a partir do levantamento das demandas de todos os órgãos do estado, mapeando-se os cursos mais solicitados.

Nessa perspectiva, a EAP nesses anos de crise, buscou através de parcerias com outras instituições suporte para a consecução de seus objetivos, especialmente no que se refere a realização de pós-graduações. Uma vez que os recursos destinados a esse fim não eram suficientes para a contratação de uma IES.

Em uma perspectiva mais genérica, para que a EAP de fato alcance sua missão institucional precisa ampliar seus serviços, porém a legislação atual acaba travando algumas parcerias, e por ser uma autarquia, poderia arrecadar recursos financeiros e assim investir na própria instituição. Para tanto, é necessário uma nova lei, um novo decreto e um novo regimento para a instituição, adequando a um novo organograma institucional.

Constatou-se ainda que muitos gestores também não possuem uma visão estratégica quanto a importância da capacitação aos servidores, pois quando se disponibiliza vagas para determinados órgãos, com perfil específico para os cursistas, o gestor não leva tais orientações em consideração e encaminha para a participação no curso, servidores que não atuam naquela função, comprometendo assim a qualidade na construção dos conhecimentos e na aplicabilidade dos conhecimentos no exercício da função pública.

Apesar das dificuldades financeiras nos anos de 2015-2016, a Escola alcançou as metas previstas no PPA, especialmente quanto aos cursos de formação e capacitação. Entretanto, nas demais atividades, a EAP não conseguiu o alcance das metas, refletindo a grande necessidade de mudança, principalmente nas legislações, a fim de tornar a instituição autossustentável.

Conhecer a EAP também sob a ótica dos servidores se fez necessário para alcançar informações de um dos atores principais dessa pesquisa, para que assim se possa mensurar questões importantes no processo de formação dos mesmos. Desta forma, foram analisadas 419 avaliações de servidores públicos estaduais de diversos órgãos da administração pública, referentes às ações de formação realizadas no período em estudo, sendo que enfatizaram ser necessária maior quantidade de vagas em determinados cursos em que pese a teoria e prática. Servidores de algumas instituições opinaram ainda que a escola busque realizar o levantamento das necessidades de capacitações juntos aos órgãos de governo e que dê a devolutiva aos mesmos sobre a possibilidade de atendimento ou não, para que assim como a exemplo do Comando Geral através da Diretoria de Ensino e Instrução possa se organizar.

Diante desse panorama geral apresentado, se verificou as percepções de vários servidores públicos, ocupantes de cargo comissionado ou não, atuando recentemente na função, ou ainda há muito tempo desempenhando seu papel de servir ao púbico, possibilitando perceber esse universo multifacetado que é a formação continuada, seus entraves e conflitos. 


\section{Considerações finais}

A intenção desta pesquisa foi avaliar a contribuição da formação continuada viabilizada pela Escola de Administração Pública para a melhoria do desempenho profissional dos servidores públicos estaduais, no período de 2013-2016.

No decorrer do estudo verificou-se com situações distintas quanto ao que fora respondido nas três instituições pesquisadas. Verificamos que tanto a Polícia Militar quanto a SEAD, enfatizaram que as que as capacitações atenderam positivamente em todos os questionamentos realizados. Parece haver uma cumplicidade quanto ao planejamento da EAP às demandas emanadas pelos dois órgãos. Entretanto, quanto ao Corpo de Bombeiros Militar do Amapá, verificou-se que a Escola de Administração tem ficado muito aquém do que àqueles servidores necessitam para suprir as demandas de capacitação.

Isto se refere aos cenários econômicos diferenciados que a EAP apresentou entre $2013 / 2014$ e 2015/2016, o que aparentemente influenciou grandemente nos tipos de capacitação disponibilizadas aos servidores públicos do estado do Amapá, haja vista que o grande anseio dos mesmos é cursarem pós-graduações a fim de se habilitarem dentro de uma determinada área e assim galgarem uma certificação com peso no mercado, bem como ampliarem suas gratificações de acordo com as progressões e ou promoções.

Outro ponto relevante que a pesquisa mostrou foi falto de acompanhamento sistematizado dos servidores referente às necessidades de capacitação e aos comportamentos apresentados no exercício da função. Assim como os servidores não têm conhecimento do papel institucional da EAP quanto as capacitações que por ela devam ser disponibilizadas.

É válido ressaltar que para se fazer permanente e validar uma sistemática de formação dessa natureza, é importante adotá-la como uma política pública, com metas de execução e principalmente de acompanhamento e avaliação por parte dos gestores, a fim de torná-la organizada e metódica, sendo mesurada através de indicadores quantitativos e qualitativos.

Desta forma, com o uso da EAD, a Escola de Administração Pública, poderia convergir seus esforços financeiros e humanos, para os maiores anseios dos servidores, ou seja, as pós-graduações lato e stricto sensu, focando nas áreas de maior necessidade para a Administração pública e de cursos que não são oferecidos no mercado local, ou focar em uma área específica, se tornando referência a exemplo do que ocorre em outras escolas de governo pelo Brasil.

Diante deste cenário apresentado e por meio das considerações aqui explicitadas, há de se ressaltar a necessidade de melhorar a política pública pela qual a EAP é responsável, onde gestores assumam sua responsabilidade em planejar e gerenciar os recursos financeiros e humanos, que os servidores compreendam que o processo de formação é condição "sine qua non" para a melhoria dos processos e conseqüentemente para qualificar as entregas dos serviços públicos à sociedade amapaense.

\section{Referências bibliográficas}

BITTENCOURT, Maryângela Aguiar, ZOUAIN, Deborah Moraes. Escolas de Governo e a Profissionalização do Servidor Público: Estudo dos Casos da Escola de Serviço Público do Estado do Amazonas - ESPEA e da Fundação. Escola de Serviço Público Municipal de 
Manaus - FESPM, ano 10, v.14, n.2, p.75-94, maio/set, 2010. Disponível em: <https://bibliotecadigital.fgv.br/dspace/handle/10438/17013.> Acesso em: 04 fev. 2019.

CAPUANO, Airton. Gestão por competências no setor público: experiências de países avançados e lições para o Brasil. Revista do Serviço Público, Brasília v.66, n.3, p. 371394 jul/set. 2015.Disponível em: $<$ https://revista.enap.gov.br/index.php/RSP/article/view/574 >. Acesso em: 5 fev. 2019.

ESCOLA DE ADMINISTRAÇÃO PÚBLICA. Manual de normas da EAP. Macapá:EAP, $2006.6 \mathrm{p}$.

FERNANDES, Ciro Campos Christo. Escolas de Governo: Conceito, Origens, Tendências e Perspectivas para sua Institucionalização no Brasil. Painel 09/027 Escolas de governo, estratégias de capacitação e gestão do conhecimento. Brasília, 2015.Disponível em: <http://www.escoladegestao.pr.gov.br/arquivos/File/2015/VIII Consad/027.pdf.> Acesso em: 14 fev. 2019.

FONSECA, Diogo Ribeiro da. Sistemas de Escolas de Governo da União: perfil, Identidade e desafios para institucionalização. Brasília: Enap, 2015. Disponível em:<http://repositorio.enap.gov.br/handle/1/1758>. Acesso em: 14 fev. 2019.

LIMA, Luciana, D’ASCENZI, Luciano. Estrutura Normativa e Implementação de Políticas Públicas. Porto Alegre:[s.n], 2014. Disponível em:<http://www.academia.edu/12657417/Estrutura_normativa_e_implementa\%C3\%A7 \%C3\%A3o_de_pol\%C3\%ADticas_p\%C3\%BAblicas>. Acesso em: 8 fev.2019

PEREIRA, Luiz Carlos Bresser. Reforma do Estado para a cidadania. São Paulo: 34, 1998. Disponível em:<https://www.estantevirtual.com.br/livros/luiz-carlos-bresserpereira/reforma-do-estado-para-a-cidadania/2293596978>. Acesso em: 1 fev. 2019.

RUA, Maria das Graças. Análise de Políticas Públicas: conceitos básicos. São Paulo:[s.n],1997. Disponível em: <https://pt.slideshare.net/carlospolicarpo/6-politicaspublicas-16048335>. Acesso em: 15 jan. 2019.

SOUZA, Celina. Políticas públicas: questões temáticas e de pesquisa. Caderno CRH, Salvador, n. 39, p.11-24, jul./dez. 2003. Disponível em:<https://edisciplinas.usp.br/pluginfile.php/359019/mod_resource/content/1/T2\%2 0Celina\%20Souza\%20Politicas\%20publicas\%20RCRH-2006-273.pdf>. Acesso em: 01 fev. 2019. 